\title{
Prevalence of Asymptomatic and/or Low-Density Malaria Infection among High-Risk Groups in Peninsular Malaysia
}

\author{
Naqib Rafieqin Noordin, ${ }^{1}$ Phone Youth Lee, ${ }^{1}$ Fatma Diyana Mohd Bukhari, ${ }^{1}$ Mun Yik Fong, ${ }^{1}$ Mohd Hafizi Abdul Hamid, ${ }^{2}$ \\ Jenarun Jelip, ${ }^{2}$ Rose Nani Mudin, ${ }^{2}$ and Yee Ling Lau ${ }^{1 \star}$ \\ ${ }^{1}$ Department of Parasitology, Faculty of Medicine, University of Malaya, Kuala Lumpur, Malaysia; ${ }^{2}$ Vector Borne Disease Sector, Ministry of Health, \\ Putrajaya, Malaysia
}

\begin{abstract}
Asymptomatic and/or low-density malaria infection has been acknowledged as an obstacle to achieving a malaria-free country. This study aimed to determine the prevalence of asymptomatic and/or low-density malaria infection in previously reported malarious localities using nested PCR in four states, namely, Johor, Pahang, Kelantan, and Selangor, between June 2019 and January 2020. Blood samples $(n=585)$ were collected and were extracted using a QIAamp blood kit. The DNA was concentrated and subjected to nested PCR. Thin and thick blood smears were examined as well. Of the 585 samples collected, 19 were positive: 10 for Plasmodium knowlesi, eight for Plasmodium vivax, and one for Plasmodium ovale. Asymptomatic and/or low-density malaria infection is a threat to malaria elimination initiatives. Eliminating countries should develop guidance policy on the importance of low-density malaria infection which includes detection and treatment policy.
\end{abstract}

Besides China and the Republic of Korea, Malaysia is on course to achieve malaria-free status by the end of $2020 .^{1}$ However, the efforts committed to achieve this status are dampened because of high proportion of Plasmodium knowlesi malaria cases reported in Malaysian Borneo ${ }^{2}$ and also in Peninsular Malaysia. ${ }^{3}$ Plasmodium knowlesi malaria has been well acknowledged and recognized as the predominant contributor to malaria cases in Malaysia, ${ }^{2,3}$ which may cause severe disease and has a fatality rate similar to that of Plasmodium falciparum infections. ${ }^{2}$

Asymptomatic and/or low-density malaria infection has been known for many years and is a result of premunition, partial immunity toward the parasite that controls the infection from becoming severe but does not obliterate the parasite. ${ }^{4}$ The term asymptomatic applies to individuals who are harboring the parasite but presenting no specific clinical manifestations of the infection. Low-density infection on the other hand implies toward infection in which the parasitemia is not being quantified via conventional diagnostic tests such as blood film malaria parasite (BFMP) or rapid diagnostic tests. Rather, this low-density infection is identified with the utilization of a highly sensitive diagnostic method, namely, PCR. ${ }^{5}$

Asymptomatic and/or low-density malaria infection is thus far an imperative obstacle in reducing the number of malaria cases worldwide as it also contributes to the transmission of $P$. knowlesi. $^{6}$ It was evident from previous studies that mosquitoes can be infected by biting children with submicroscopic gametocytemia. Although infectivity is lower than microscopic gametocytemia infections, transmission of submicroscopic infection to a mosquito serves as an important precursor for subsequent infections. ${ }^{7}$ The gold standard of malaria diagnosis is BFMP. However, because of its low detection limit, a vast array of molecular methods has been implemented to supplement the BFMP results. Of these, nested PCR or real-time PCR is widely used with a detection limit of 100-1,000 parasites per milliliter of blood ${ }^{8}$ as

*Address correspondence to Yee Ling Lau, Department of Parasitology, Faculty of Medicine, University of Malaya, Kuala Lumpur 50603, Malaysia. E-mail: lauyeeling@um.edu.my compared with 10,000-100,000 parasites per milliliter of blood for BFMP. 9

This study aimed to screen for the presence of low-density malaria infection among asymptomatic communities living in high-transmission areas of malaria in Peninsular Malaysia via a molecular method. A total of 667 and 760 malaria cases were reported in Peninsular Malaysia in 2017 and 2018, respectively (Ministry of Health Malaysia, unpublished data). This crosssectional study has covered four states with the highest incidence rate of malaria in Peninsular Malaysia, Johor (81 and 64 cases in 2017 and 2018, respectively), Pahang (85 and 123 cases in 2017 and 2018, respectively), Kelantan (168 and 135 cases in 2017 and 2018, respectively), and Selangor (105 and 102 cases in 2017 and 2018, respectively), and was conducted from June 2019 to January 2020. Sampling was conducted in districts with previously reported malaria cases including Mersing, Kota Tinggi, and Kluang in Johor; Kuala Lipis, Maran, and Jerantut in Pahang; Gua Musang in Kelantan; and Hulu Selangor and Hulu Langat in Selangor. These districts have been selected as the cases of malaria reported were high in 2017 and 2018 (Ministry of Health Malaysia, unpublished data), and thus, this study hypothesized the presence of asymptomatic and/or low-density malaria infection among the communities of high-risk groups. Here, a high-risk group is defined as individuals working in proximity with forest and forest fringes, for instance, servicemen, farmers, hunters, and natural resource collectors as described previously. ${ }^{10,11}$ Close-contact individuals in the same village of previously reported cases were also recruited voluntarily in this study. In brief, the study sites were selected based on previously reported malaria incidence, whereas the respondents were recruited based on close proximity with the index's house (typically of the same village) as well as high-risk group individuals.

Approximately, $5 \mathrm{~mL}$ of whole blood from consenting respondents was collected in a heparinized blood collection tube for analysis via nested PCR and blood film examination. Demographic data of the respondents, history of experiencing any symptoms of malaria, previous malarial infection, and visit to forest or agricultural areas were collected as well. This study has been approved by the Medical Research Subcommittee of the Malaysian Ministry of Health (NMRR-15-67223975). 
Thin and thick blood films were prepared using a few drops of heparinized whole blood within 5 hours of sample collection. Thin blood films were fixed with methanol and stained immediately with $10 \%$ Giemsa for 20 minutes and air-dried. Thick films were air-dried overnight before staining with $10 \%$ Giemsa. For extraction of DNA, $1 \mathrm{~mL}$ of whole blood was centrifuged at $1,200 \times \mathrm{g}$ for 10 minutes to remove plasma and buffy coat. The packed RBC (pRBC) was then stored in liquid nitrogen temporarily ( $1-5$ days) and then frozen at $-80^{\circ} \mathrm{C}$. Two hundred to $600 \mu \mathrm{L}$ of pRBC was extracted using a QIAamp blood mini kit or QIAamp blood midi kit (Qiagen, Hilden, Germany). The extracted DNA was concentrated until $10 \mu \mathrm{L}$ of sample left in the microcentrifuge tube. The equivalent of 200 $\mu \mathrm{L}$ of whole blood was screened using nested PCR.

Extracted DNA was subjected to nested PCR assays targeting the Plasmodium 18S small subunit ribosomal RNA in which the primer pair rPLU1 and rPLU5 was used in nest 1, whereas primer pair rPLU3 and rPLU4 was used in nest $2 .^{8}$ Should positive amplification observed on the second round of amplification, the product of the first round amplification would be subjected to species detection using speciesspecific primer pairs: rFAL1 and rFAL2, rMAL1 and rMAL2, rVIV1 and rVIV2, rOVA1 and rOVA2 ${ }^{8}$ and PkF1140 and PkR1550. ${ }^{12}$ The cycle profiling used was as per described. ${ }^{12}$ Products of nest 2 were electrophoresed and visualized. Species-specific PCR products were directly ligated into pGEM $^{\circledR}-\mathrm{T}$ (Promega, WI) and transformed into One Shot ${ }^{\mathrm{TM}}$ TOP10F' Chemically Competent Escherichia coli (Invitrogen). Positive recombinant plasmids were sent to First BASE Laboratories Sdn. Bhd., Malaysia, and DNA sequences were then subjected to BLAST analysis for confirmation of species identity. Then, re-extraction of positive samples was performed for loop-mediated isothermal amplification (LAMP) analysis to further validate the results.
A total of 585 blood samples were collected from June 2019 to January 2020, of which 217 blood samples were collected from army personnel. The demographic data of the study locations are shown in Table 1. Majority $(73.8 \%)$ of the respondents were males $(n=432)$, and $79.0 \%(n=462)$ of the respondents were in the $15-45$ years age-group. Most of the respondents were healthy $(96.1 \%, n=562)$, not experiencing any signs and symptoms for malaria, specifically high fever, chills, tremors, or headaches. The rest of the respondents $(3.9 \%)$ self-reported fever and/or headache, but on nested PCR, they were negative for malaria. A small proportion (5.8\%, $n=34)$ had acquired malaria previously, and $67.2 \%(n=397)$ stated that they had been to malaria-prone areas such as jungle fringes, rubber, and palm oil plantations. Of the 585 samples, 19 (3.3\%) were positive for malaria parasites as tested by nested PCR (Table 2). All subjects who were positive, 19 (100\%), sustain asymptomatic and low-density infection. Plasmodium knowlesi was found to be the predominant species (52.6\%; $n=10)$ followed by Plasmodium vivax $(42.1 \% ; n=8)$. Plasmodium ovale $(5.3 \% ; n=1)$, although rare in Malaysia, was also found in this study. None of the samples were positive when tested by BFMP. Eleven (57.9\%) of the positive respondents were army personnel who frequented forests during training, and $16(84.2 \%)$ of the 19 positive respondents did visit forest or agricultural areas before 3 months from the date of blood collection.

A cohort study on untreated asymptomatic $P$. falciparum infection among west Kenyan children by Bousema et al. reported patients with gametocytemia in the absence of treatment and thus, acting as a disease reservoir. ${ }^{13}$ This finding is contradictory to the fundamental theory of the production of gametocytes. Differentiation from trophozoites to gametocytes in $P$. falciparum is generally governed by stimulants or stressors such as antimalarial drugs which target the asexual

TABLE 1

Demographic data of the study sites

\begin{tabular}{|c|c|c|c|c|c|c|c|c|c|c|}
\hline \multirow[b]{4}{*}{ Characteristic } & \multicolumn{9}{|c|}{ Study population, \% (No.) } & \multirow[b]{4}{*}{ Total \% (No.) } \\
\hline & \multicolumn{9}{|c|}{ State } & \\
\hline & \multicolumn{3}{|c|}{ Johor } & \multicolumn{3}{|c|}{ Pahang } & \multirow{2}{*}{$\frac{\text { Kelantan }}{\text { Gua Musang }}$} & \multicolumn{2}{|c|}{ Selangor } & \\
\hline & Kota Tinggi & Kluang & Mersing & Kuala Lipis & Maran & Jerantut & & Hulu Langat & Hulu Selangor & \\
\hline No. of samples & $26.5(155)$ & $17.3(101)$ & $2.8(16)$ & $11.1(65)$ & $2.1(12)$ & $3.4(20)$ & $24.4(143)$ & $8.0(47)$ & $4.4(26)$ & $100(585)$ \\
\hline \multicolumn{11}{|l|}{ Gender } \\
\hline Male & $72.9(113)$ & $99.0(100)$ & $100(16)$ & $55.4(36)$ & $75.0(9)$ & $50.0(10)$ & $64.3(92)$ & $95.7(45)$ & $42.3(11)$ & $73.8(432)$ \\
\hline Female & $27.1(42)$ & $1.0(1)$ & 0 & $44.6(29)$ & $25.0(3)$ & $50.0(10)$ & $35.7(51)$ & $4.3(2)$ & $57.7(15)$ & $26.2(153)$ \\
\hline \multicolumn{11}{|l|}{ Age (years) } \\
\hline $15-45$ & $74.8(116)$ & $99.0(100)$ & $100(16)$ & $75.4(49)$ & $41.7(5)$ & $45.0(9)$ & $84.6(121)$ & $66.0(31)$ & $57.7(15)$ & $79.0(462)$ \\
\hline $46-60$ & $9.7(15)$ & 0 & 0 & $10.8(7)$ & $16.6(2)$ & $25.0(5)$ & $9.1(13)$ & $6.4(3)$ & $27.0(7)$ & $8.9(52)$ \\
\hline$>60$ & $3.2(5)$ & 0 & 0 & $13.8(9)$ & $41.7(5)$ & $30.0(6)$ & $6.3(9)$ & 0 & $15.3(4)$ & $6.5(38)$ \\
\hline Undetermined & $12.3(19)^{*}$ & $1.0(1)^{\star}$ & 0 & 0 & 0 & 0 & 0 & $27.6(13)^{\star}$ & 0 & $5.6(33)$ \\
\hline \multicolumn{11}{|c|}{ Self-reporting malaria } \\
\hline \multicolumn{11}{|c|}{ symptoms } \\
\hline Yes & $2.6(4)$ & $99.0(1)$ & $6.3(1)$ & $4.6(3)$ & $8.3(1)$ & $15.0(3)$ & $5.6(8)$ & 0 & $7.7(2)$ & $3.9(23)$ \\
\hline No & $97.4(151)$ & $1.0(100)$ & $93.7(15)$ & $95.4(62)$ & $91.7(11)$ & $85.0(17)$ & $94.4(135)$ & $100(47)$ & $92.3(24)$ & $96.1(562)$ \\
\hline \multicolumn{11}{|l|}{$\begin{array}{l}\text { Previous history of } \\
\text { malaria infection }\end{array}$} \\
\hline Yes & $1.9(3)$ & 0 & $6.3(1)$ & $12.3(8)$ & $8.3(1)$ & $20.0(4)$ & $9.8(14)$ & 0 & $11.5(3)$ & $5.8(34)$ \\
\hline No & $98.1(152)$ & $100(101)$ & $93.7(15)$ & $87.7(57)$ & $91.7(11)$ & $80.0(16)$ & $90.2(129)$ & $100(47)$ & $88.5(23)$ & $94.2(551)$ \\
\hline \multicolumn{11}{|c|}{$\begin{array}{l}\text { Visit to forest or } \\
\text { agricultural areas }\end{array}$} \\
\hline Yes & $79.4(123)$ & $99.0(1)$ & $100(16)$ & $58.5(38)$ & $66.7(8)$ & $85.0(17)$ & $84.6(121)$ & $100(47)$ & $100(26)$ & $67.9(397)$ \\
\hline No & $20.6(32)$ & $1.0(100)$ & 0 & $41.5(27)$ & $33.3(4)$ & $15.0(3)$ & $15.4(22)$ & 0 & 0 & 32.1 (188) \\
\hline
\end{tabular}


TABLE 2

Species profile corresponding to the districts

\begin{tabular}{|c|c|c|c|c|c|c|c|c|c|}
\hline \multirow[b]{3}{*}{ Species } & \multicolumn{9}{|c|}{ State } \\
\hline & \multicolumn{3}{|c|}{ Johor } & \multicolumn{3}{|c|}{ Pahang } & \multirow{2}{*}{$\frac{\text { Kelantan }}{\text { Gua Musang }}$} & \multicolumn{2}{|c|}{ Selangor } \\
\hline & Kota Tinggi & Kluang & Mersing & Kuala Lipis & Maran & Jerantut & & Hulu Langat & Hulu Selangor \\
\hline Plasmodium falciparum & 0 & 0 & 0 & 0 & 0 & 0 & 0 & 0 & 0 \\
\hline Plasmodium knowlesi & 6 & 3 & $1^{*}$ & 0 & 0 & 0 & 0 & 0 & 0 \\
\hline Plasmodium vivax & 2 & 2 & 1 & 0 & 1 & 0 & 0 & 0 & 2 \\
\hline Plasmodium malariae & 0 & 0 & 0 & 0 & 0 & 0 & 0 & 0 & 0 \\
\hline Plasmodium ovale & 1 & 0 & 0 & 0 & 0 & 0 & 0 & 0 & 0 \\
\hline
\end{tabular}

erythrocytic stage of the parasite or other antipyretic drugs and herbal compounds. ${ }^{14}$ Similar study has not been carried out on $P$. knowlesi because of the failure in inducing gametocytogenesis toward in vitro-adapted $P$. knowlesi lines. ${ }^{15}$ Knowledge with regard to the development and longevity of $P$. knowlesi gametocytes in the human host is scarce. Gametocytes in the blood can be transmitted to other individuals, hence sustaining the transmission. In our study, the respondents were asymptomatic and most likely with low-density parasitemia; however, no parasite was seen under microscopic examination. Drug-induced release of gametocytes is unlikely as these individuals were not treated with antimalarials.

Our findings unveiled the presence of asymptomatic and/or low-density malaria infection among high-risk groups, such as military personnel, community in close proximity to jungle fringe, and people with a history of previous malaria infection. This study also found that asymptomatic and/or low-density malaria infection could occur not only in $P$. vivax malaria but also in $P$. knowlesi and $P$. ovale malaria. In Malaysia, only four studies $^{7,16-18}$ on asymptomatic and/or low-density malaria infection were reported. Plasmodium vivax, followed by $P$. knowlesi, was the main parasite in asymptomatic and/or low-density malaria infection in Malaysian Borneo. Results in our study are consistent with previous studies ${ }^{6,17}$ where $P$. knowlesi accounted for majority of the positive cases. On the contrary, Jiram and her group found $P$. vivax as the predominant species in asymptomatic and/or low-density malaria infection in Belaga district, Kapit division, Sarawak. ${ }^{16,18}$ This could be due to the fact that these samples were collected during a $P$. vivax outbreak. ${ }^{18}$

Several countries in Southeast Asia have embarked on asymptomatic and/or low-density malaria infection-associated studies such as Indonesia, ${ }^{19}$ Myanmar, and Thailand. ${ }^{20}$ These countries are categorized as low-transmission areas where malaria is hypoendemic. ${ }^{18}$ Plasmodium vivax was found to be the most prevalent species in these countries, and it poses unique challenges because the dormant hypnozoites can reactivate and differentiate into blood-stage merozoites and gametocytes. Asymptomatic $P$. vivax malaria is a common form of asymptomatic and/or low-density malaria infection in these low-transmission malarious areas. A limitation of this study is the small sample size; thus, our finding may not represent the whole population of high-risk groups in Peninsular Malaysia for asymptomatic and/or low-density malaria infection.

Partial immunity has been thought to be the possible reason for asymptomatic malaria infection. Such immunity is seen in individuals who are exposed to several genetically prominent clones of the parasite. ${ }^{21}$ In highly endemic malarious areas, the locals are exposed to multiple clone inoculations, resulting in acute development of immunity against the disease as well as asymptomatic infections. ${ }^{22}$ Hence, throughout the infection, one is either asymptomatic as the individual clears up parasites in the blood, aided by antimalarial drugs, or is developing symptomatic infection.

Asymptomatic and/or low-density malaria infection could be an obstacle to the malaria elimination initiative by the Ministry of Health for several reasons. First, asymptomatic and/or low-density malaria infection could potentially be a source of sustained transmission in the community. Besides, detection of low-density malaria infection requires the use of highly sensitive methods such as molecular-based assay, and there has not been clear guidance policy on the use of molecular-based assay in detection of low-density malaria infection. It is important to note that there is no clear guidance policy on treatment of low-density malaria infection as well.

In brief, asymptomatic and/or low-density malaria infection is a threat to malaria elimination initiatives. Eliminating countries should develop guidance policy on the importance of low-density malaria infection which includes detection and treatment policy to fortify the modus operandi of eliminating malaria in this country.

Received April 10, 2020. Accepted for publication May 12, 2020.

Published online July 6, 2020.

Acknowledgments: We sincerely thank the local health officers and the staff from Mersing, Kota Tinggi, and Kluang (Johor); Kuala Lipis, Maran, and Jerantut (Pahang); Gua Musang (Kelantan); and Hulu Selangor and Hulu Langat (Selangor) who had helped in sampling.

Financial support: This project is supported by the Ministry of Education Malaysia (long-term research grant scheme LR002D-2018).

Authors' addresses: Naqib Rafieqin Noordin, Phone Youth Lee, Fatma Diyana Mohd Bukhari, Mun Yik Fong, and Yee Ling Lau, Department of Parasitology, Faculty of Medicine, University of Malaya, Kuala Lumpur, Malaysia, E-mails: naqibrafieqin.nr@gmail.com, zen1py@hotmail.com, fatma_diyana@yahoo.com, fongmy@um.edu.my, and lauyeeling@ um.edu.my. Mohd Hafizi Abdul Hamid, Jenarun Jelip, and Rose Nani Mudin, Vector Borne Disease Sector, Ministry of Health, Putrajaya, Malaysia, E-mails: dr.mhafizi@moh.gov.my, jenarun@moh.gov.my, and drrose@moh.gov.my.

\section{REFERENCES}

1. World Health Organization, 2019. Malaysia E-2020 Country Brief. Available at: https://https://www.who.int/malaria/areas/elimination/ e2020/malaysia/en/. Accessed December 10, 2019.

2. Barber BE, William T, Grigg MJ, Menon J, Auburn S, Marfurt J, Anstey NM, Yeo TW, 2013. A prospective comparative study of knowlesi, falciparum, and vivax malaria in Sabah, Malaysia: high proportion with severe disease from Plasmodium knowlesi 
and Plasmodium vivax but no mortality with early referral and artesunate therapy. Clin Infect Dis 56: 383-397.

3. Yusof R, Lau YL, Mahmud R, Fong MY, Jelip J, Ngian H, Mustakim S, Hussin HM, Marzuki N, Ali MM, 2014. High proportion of knowlesi malaria in recent malaria cases in Malaysia. Malar J 13: 168.

4. Doolan DL, Dobaño C, Baird JK, 2009. Acquired immunity to malaria. Clin Microbiol Rev 22: 13-36.

5. World Health Organization, 2017. Meeting Report of the WHO Evidence Review Group on Low-Density Malaria Infections. Available at: https://www.who.int/malaria/mpac/mpac-oct2017erg-malaria-low-density-infections-session2.pdf?ua=1. Accessed April 2, 2020.

6. Fornace KM, Nuin NA, Betson M, Grigg MJ, William T, Anstey NM, Yeo TW, Cox J, Ying LT, Drakeley CJ, 2016. Asymptomatic and submicroscopic carriage of Plasmodium knowlesi malaria in household and community members of clinical cases in Sabah, Malaysia. J Infect Dis 212: 784-787.

7. Schneider P, Bousema JT, Gouagna LC, Otieno S, van de VegteBolmer M, Omar SA, Sauerwein RW, 2007. Submicroscopic Plasmodium falciparum gametocyte densities frequently result in mosquito infection. Am J Trop Med Hyg 76: 470-474.

8. Snounou G, Viriyakosol S, Jarra W, Thaithong S, Brown K, 1993. Identification of the four human malaria parasite species in field samples by the polymerase chain reaction and detection of a high prevalence of mixed infections. Mol Biochem Parasitol 58: 283-292.

9. Trampuz A, Jereb M, Muzlovic I, Prabhu RM, 2003. Clinical review: severe malaria. Crit Care 7: 315-323.

10. Singh B, Lee KS, Matusop A, Radhakrishnan A, Shamsul SS, CoxSingh J, Thomas A, Conway DJ, 2004. A large focus of naturally acquired Plasmodium knowlesi infections in human beings. Lancet 363: 1017-1024.

11. Wong PSJ, Tan CH, Lee V, Li MZI, Lee KS, Lee PJ, Singh B, Ng LC, 2011. Molecular epidemiological investigation of Plasmodium knowlesi in humans and macaques in Singapore. Vector Borne Zoonotic Dis 11: 131-135.

12. Imwong M, Tanomsing N, Pukrittayakamee S, Day NPJ, White NJ, Snounou G, 2009. Spurious amplification of a Plasmodium vivax small-subunit RNA gene by use of primers currently used to detect $P$. knowlesi. J Clin Microbiol 47: 4173-4175.
13. Bousema JT, Gouagna LC, Drakeley CJ, Meutstege AM, Okech BA, Akim INJ, Beier JC, Githure JI, Sauerwein RW, 2004. Plasmodium falciparum gametocyte carriage in asymptomatic children in western Kenya. Malar J 3: 1-6.

14. Dixon MWA, Thompson J, Gardine DL, Trenholme KR, 2008. Sex in Plasmodium: a sign of commitment. Trends Parasitol 24: 168-175.

15. Moon RW, Hall J, Rangkuti F, Ho YS, Almond N, Mitchell GH, Arnab P, Holder AP, Blackman MJ, 2013. Adaptation of the genetically tractable malaria pathogen Plasmodium knowlesi to continuous culture in human erythrocytes. Proc Natl Acad Sci USA 110: 531-536.

16. Jiram AI, Hisam S, Reuben H, Husin SZ, Roslan A, Wan WRI, 2016. Submicroscopic evidence of the simian malaria parasite, Plasmodium knowlesi, in an Orang Asli community. Southeast Asian J Trop Med Publ Health 47: 591-599.

17. Siner A, Liew ST, Kadir KA, Mohamad DSA, Thomas FK, Zulkarnaen M, Singh B, 2017. Absence of Plasmodium inui and Plasmodium cynomolgi, but detection of Plasmodium knowlesi and Plasmodium vivax infections in asymptomatic humans in the Betong division of Sarawak, Malaysian Borneo. Malar J 16 : $1-11$.

18. Jiram Al, Ooi CH, Rubio JM, Hisam S, Karnan G, Sukor NM, Artic MM, Ismail NP, Alias NW, 2019. Evidence of asymptomatic submicroscopic malaria in low transmission areas in Belaga district, Kapit division, Sarawak, Malaysia. Malar J 18: 1-12.

19. Lubis IND, Wijaya H, Lubis M, Lubis CP, Divis PCS, Beshir KB, Sutherland CJ, 2017. Contribution of Plasmodium knowlesi to multispecies human malaria infections in north Sumatera, Indonesia. J Infect Dis 215: 1148-1155.

20. Li P et al., 2014. Nested PCR detection of malaria directly using blood filter paper samples from epidemiological surveys. Malar J 13: 175.

21. Filipe JAN, Riley E, Drakeley CJ, Sutherland CJ, Ghani AC, 2007. Determination of the processes driving the acquisition of immunity to malaria using a mathematical transmission model. PLoS Comput Biol 3: 2569-2579.

22. Magesa SM, Mdira KY, Babiker HA, Alifrangis M, Färnert $A$, Simonsen PE, Bygbjerg IC, Walliker D, Jakobsen PH, 2002. Diversity of Plasmodium falciparum clones infecting children living in a holoendemic area in north-eastern Tanzania. Acta Trop 84: 83-92. 